\title{
Enhancement of furfural-cyclopentanone aldol condensation using binary water-ethanol mixtures as solvent
}

\author{
Jennifer Cueto, Laura Faba, Eva Díaz, Salvador Ordóñez
}

4 Department of Chemical and Environmental Engineering, University of Oviedo, Julián

5 Clavería s/n, 33006 Oviedo, Spain

6 BACKGROUND: Cyclopentanone (CPO) - furfural (FFL) aldol condensation is a very interesting 7 reaction for upgrading the furfural obtained in the depolymerization - dehydration reaction of 8 cellulosic materials. Reaction is faster with cyclopentanone than with other ketones, and 9 resulting condensation adducts are attractive for manufacturing drop - in fuels. However, the 10 most important problem is that this adducts present low water solubility.

11 RESULTS: Binary systems combining water (needed to promote the aldol condensation) and 12 ethanol (for enhancing the condensation adducts solubility) at different ratios have been 13 tested. Operation parameters, such as water/ethanol ratio, temperature and reaction time, 14 were optimized for this reaction. Best results (global yield to condensation adducts higher than $1536 \%$ ) were achieved using 1:2 water/ethanol ratio, and working at $303 \mathrm{~K}$. Higher water ratios 16 lead to the precipitation of condensation products, whereas higher ethanol concentrations 17 hinder the catalyst performance. A reaction mechanism, considering a first order kinetic model 18 on cyclopentanone concentration, was proposed. Kinetic constants have been empirically correlated with ethanol concentration in the reaction medium.

CONCLUSIONS: The use of binary ethanol-water binary mixtures with controlled solvent ratios can avoid the precipitation of condensation adducts. This precipitation leads to important operation problems in the reactor as well as to catalyst deactivation. The negative effect of the presence of ethanol on the reaction kinetics can be overcome by increasing reaction temperature.

KEYWORDS. Biorefinery; cyclopentanone; furfural; solvent effects; drop-in diesel fuels; 


\section{INTRODUCTION}

29 The increasing concern about global climate change has promoted the development of 30 different routes that use biomass waste as raw material for obtaining biofuels and 31 commodity chemicals ${ }^{1}$. One of the most promising routes to fulfil these purposes is the 32 aqueous phase transformation of lignocellulosic biomass ${ }^{2}$. Aldol condensation can be a 33 key step for these purposes, since it is an effective way for the selective conversion of 34 small molecules (C5-C6) into larger ones with 8 to 15 carbon atoms ${ }^{3,4}$. These 35 condensation adducts are precursors for a large variety of renewable chemicals and, upon total hydrogenation, drop-in diesel fuels. Aldol condensation involves the

37 interaction between two molecules with carbonyl groups (aldehydes - furfural FFL or 385 -hydroximethylfurfural 5 - HMF - or ketones), being acetone the most studied 39 linking molecule ${ }^{5-8}$.

40 There are several studies about the aldol condensation of acetone and furfural or 541 HMF using different homogeneous and heterogeneous catalysts, highlighting different 42 hydroxides $\left(\mathrm{NaOH} \text { and } \mathrm{Ca}(\mathrm{OH})_{2}\right)^{9,10}$ and mixed oxides such as $\mathrm{Mg}-\mathrm{Zr}$ or $\mathrm{Mg}-\mathrm{Al}^{5,8}$. 43 However, there are other bio-derived molecules with two $\alpha$-hydrogen positions that 44 can be alternatively used for this purpose. Among these compounds, cyclopentanone (CPO) presents important advantages in comparison to acetone. Firstly, resulting

46 condensation adducts are entirely renewable since both reactants (cyclopentanone 47 and furfural or 5-HMF) can be quantitatively produced from ligno-cellulosic biomass ${ }^{11}$, 48 whereas acetone is nowadays only renewably obtained as a side product in the ABE 49 fermentation. On the other hand, considering the usefulness of the resulting products, 50 condensation adducts obtained have longer and branched carbon chains, leading to 
51 fuels of better quality ${ }^{12}$. Despite these theoretical considerations, cyclopentanone-

52 furfural condensation is still scarcely studied. Hronec et al. studied this reaction using

53 homogeneous catalyst $(\mathrm{NaOH})$, with more than $95 \%$ of the second adduct yield $(\mathrm{C} 15)$

54 in less than two hours ${ }^{13}$. Deng et al. reported selectivities higher than $85 \%$ (in solid

55 phase) after 2 hours but working in solvent-free condensation and using $\mathrm{NaOH}$ as

56 catalyst $^{14}$.

57 In spite of the well-known disadvantages of using homogeneous catalysts ${ }^{15}$, and the

58 wide use of solid base catalysts for these reactions ${ }^{7,16,17}$ there are few works dealing

59 with the heterogeneously catalyzed cyclopentanone-furfural condensation ${ }^{18}$. In our

60 previous work, preliminary results using Mg-Zr mixed oxide as catalyst were reported,

61 combining mild conditions $(303-323 \mathrm{~K})$ and aqueous media ${ }^{12}$. A complete conversion

62 of furfural, with more than $68 \%$ of CPO conversion, was observed after 4 hours of

63 reaction in a batch reactor. These results correspond to a 320 times faster reaction

64 than the similar tests using acetone as linking molecule ${ }^{7}$. At this time, the carbon

65 balance closure in liquid phase decreases to $20 \%$ and main products were obtained as

66 solids, reaching a global yield of $77 \%$. The low solubility of these adducts in water,

67 hinders further downstream processing, such as partial or total hydrogenations.

68 Furthermore, the precipitation of these phases leads to catalyst fouling and

69 deactivation. Performing the reaction in presence of organic solvents would be an

70 alternative for overcoming these solubility problems. The high solubility of these

71 adducts in these solvents was previously observed by Hronec et al., proposing the use

72 of methanol or tetrahydrofuran ${ }^{13}$. Nevertheless, both solvents are considering as toxic

73 and incompatible with Green Chemistry principles ${ }^{19,} 20$. 
74 Taking into account that alcohols and organic esters dissolve the condensation

75 adducts $^{21}$, ethanol and ethyl acetate are proposed as valuable alternatives. Ethyl

76 acetate is considered as a green solvent (low toxicity, stable, biodegradable, etc. $)^{22}$ and

77 it was used in our previous work for fully solving the condensation adducts ${ }^{12}$ and

78 would allow studying the reaction in a biphasic system. On the other hand, ethanol is a

79 green solvent, which can be obtained from lignocellulose feedstock, reducing

80 greenhouse gas emissions in its production ${ }^{23}$ and it is less toxic than methanol (TLV is

$811000 \mathrm{ppm}$; whereas for methanol is $200 \mathrm{ppm})^{24}$. Since ethanol is soluble in water, the

82 reaction will be carried out in a binary but monophasic configuration.

83 In this paper, we try to select appropriate solvent (ethyl acetate, ethanol, and biphasic

84 or monophasic mixtures of these solvents with water), as well as to study the influence

85 of different parameters (initial volume ratios, time and temperature) in furfural -

86 cyclopentanone condensation at mild conditions, using MgZr mixed oxide as catalyst

87 and analysing the reaction mechanism as function of the obtained data.

2. Materials and methods

\subsection{Catalysts preparation}

$91 \mathrm{MgZr}$ mixed oxide with a $\mathrm{Mg} / \mathrm{Zr}$ ratio of 4 was synthesized using the sol-gel technique optimized in our previous works ${ }^{7,8}$. The gel was obtained dissolving nitrate salts in $1 \mathrm{~L}$ of deionized water and adding $\mathrm{NaOH}$ until $\mathrm{pH} 10$ to produce the precipitation. The resulting solid was aged for $24 \mathrm{~h}$ at $353 \mathrm{~K}$, filtered and washed with deionized water until $\mathrm{pH}$ 7. It was dried at $393 \mathrm{~K}$ for $24 \mathrm{~h}$ and, finally, it was calcined in He flow at 5 
$96 \mathrm{~K} \cdot \mathrm{min}^{-1}$ until $873 \mathrm{~K}$ and the temperature was held for $3 \mathrm{~h}$. All the characterization

97 results have been studied in detail in a previous work ${ }^{7}$.

Reactions were carried out in a $0.5 \mathrm{~L}$ stirred batch autoclave reactor equipped with a

100 PID temperature controller and a backpressure regulator (Autoclave Engineers EZE

101 Seal). The reactor was loaded with $0.25 \mathrm{~L}$ of a mixture of both reactants,

102 cyclopentanone (Sigma Aldrich, 99\%) and furfural (Sigma Aldrich, 99\%), with a 5 wt.\%

103 of cyclic molecules in solution. The CPO:FFL initial ratio was 1:1 and $0.1 \mathrm{~g}$ of $\mathrm{MgZr}$ oxide

104 (average diameter of $50-80 \mu \mathrm{m}$ ) was used as heterogeneous catalyst. Different

105 solvents have been tested (ethyl acetate, ethanol, water, or water-organic solvent

106 mixtures), varying the water/organic solvent volume ratios from 1:1 to 1:4 depending

107 on the experiment. The mixture was heated up to reaction temperature, air was

108 purged with $\mathrm{N}_{2}$ and the reaction took place under 10 bar of $\mathrm{N}_{2}$ with a stirring of 1000

$109 \mathrm{rpm}$ for different times. In order to evaluate the reaction evolution, samples were

110 taken from the sampling port, filtered and analysed by gas chromatography in a

111 Shimadzu GC-2010 equipped with a FID detector (using a $30 \mathrm{~m}$ long CP-Sil 8 CB

112 capillary column). The identification of the main products was verified with GC-MS in a

113 Shimadzu GC/MS QP2010 Plus instrument, using a $30 \mathrm{~m}$ long TRB-5MS capillary

114 column. Calibration of cyclopentanone and furfural were done using commercial

115 standards, whereas for the condensation adducts the relative carbon concept

116 proposed by Scanlon ${ }^{25}$ was used. Conversion, atomic yields and carbon balance

117 (equations $1-3$ ) were calculated according to the following expressions.

$$
\Psi_{C 10} \%=\frac{10 \cdot \mathrm{mol} \mathrm{C10}}{5 \cdot \mathrm{mol} \mathrm{FFL}_{t=0}+5 \cdot \mathrm{mol} \mathrm{CPO}_{t=0}} \cdot 100
$$




$$
\begin{gathered}
\Psi_{C 15} \%=\frac{15 \cdot \mathrm{mol} \mathrm{C15}}{5 \cdot \mathrm{mol} \mathrm{FFL}_{t=0}+5 \cdot \mathrm{mol} \mathrm{CPO}_{t=0}} \cdot 100 \\
\text { C.B. }(\%)=\frac{5 \cdot \mathrm{mol} \mathrm{FFL}+5 \cdot \mathrm{mol} \mathrm{CPO}+10 \cdot \mathrm{mol} \mathrm{C} 10+15 \cdot \mathrm{mol} \mathrm{C15}}{5 \cdot \mathrm{mol} \mathrm{FFL} L_{t=0}+5 \cdot \mathrm{mol} \mathrm{CPO} O_{t=0}} \cdot 100
\end{gathered}
$$

121 The final solid (either spent catalyst or a combination of the catalyst with the 122 precipitated condensation adducts) was recovered, filtered, dissolved in organic

123 solvent, and analyzed using the GC-FID (organics) or ICP-MS (metal leaching).

124 Conversions obtained in previous experiments performed in absence of $\mathrm{Mg}$ - $\mathrm{Zr}$ were negligible (less than $1 \%$ of conversion after 4 hours of reaction), discarding the

126 presence of non-catalytic mechanisms. Furthermore, the self-condensation of these compounds (CPO or FFL) was discarded because no products were detected after 4 hours if only one reactant (and the catalyst) is present in the reactor. Only a weak signal evidencing the reaction between furfural and ethanol was observed. However,

130 the relevance of this reaction of formation of acetal is almost negligible in all the cases,

131 with maximum concentrations lower than $0.0005 \mathrm{~mol} \cdot \mathrm{L}^{-1}$.

\section{Results and discussion}

\subsection{Solvent selection}

Preliminary solubility analyses of solids obtained after reaction in aqueous phase were

136 carried out to identify the most appropriate organic solvents to perform this study.

137 With this aim, non-polar compounds (hexane, diethyl ether), organic alcohols

138 (methanol, ethanol) and aprotic polar organic compounds (THF, ethyl acetate) were 139 tested, concluding that C15 adducts are entirely soluble in ethyl acetate, THF, 140 methanol and ethanol. These results are congruent with the previously observed 
141 behaviour for similar reactions, obtaining a good correspondence between the

142 solubility and the dielectric constant of these solvents. This effect is even more evident

143 in the case of alcohols, because of their both hydrophilic and hydrophobic groups that

144 produce a strong interaction between the solvent and the steric arrangement of these

145 molecules, increasing their solubility ${ }^{26}$. Methanol and THF were discarded because of

146 environmental considerations.

147 Initial tests were carried out using ethanol and ethyl acetate in a monophasic system.

148 In both cases, the reaction does not take place, obtaining less than $1 \%$ of

149 cyclopentanone conversion after $4 \mathrm{~h}$ reaction time. The only reaction observed was

150 the formation of furfural-ethanol acetal, when the alcohol was used as solvent. These

151 results suggest that water is required to perform the reaction. However, as it was

152 proved in our previous results, the adduct insolubility limits the results and leads to

153 severe catalyst deactivation ${ }^{12}$. According to these facts, a mixture of both solvents

154 (water/ethyl acetate or water/ethanol) was selected in order to improve catalytic

155 performance, avoiding the problems coming from adducts precipitation. Fig. 1 shows

156 the results (considering only liquid phase analyses) after $4 \mathrm{~h}$ of reaction at $303 \mathrm{~K}$, using

157 a 1:1 mixture of water/ethyl acetate (biphasic system) and 1:1 water/ethanol

158 (monophasic system). Results previously obtained in aqueous phase were also

159 included for comparison purposes ${ }^{12}$. ICP analyses of the liquid phase after each

160 reaction were carried out in order to discard metal lixiviation and the subsequent

161 homogeneous reaction pathway. For all the cases, negligible metal concentrations (Mg

162 and $\mathrm{Zr}$ ) were detected. The carbon balances with both water-organic solvent systems

163 exceeds $90 \%$ versus $24 \%$ working in aqueous phase (considering only liquid phase

164 species). In contrast, conversions of furfural and cyclopentanone decrease to 30 and 
$16529 \%$, respectively in the case of water/ethanol, and to 7 and $10 \%$, respectively in the

166 case of water/ethyl acetate, whereas in aqueous phase values of 98 and $66 \%$ of FFL

167 and CPO were achieved. The atomic yields of both adducts (C10 and C15) are higher

168 when using the water/ethanol mixture as solvent, obtaining a global yield of $29.6 \%$.

169 This value decreases to $6.4 \%$ in water and $1.15 \%$ in water/ethyl acetate. Separate

170 experiments were performed with both water/ethanol and water/ethyl acetate

171 systems at lower stirring velocity (600 rpm). In the first case, results obtained at 600

$172 \mathrm{rpm}$ were very similar to the previously reported experiments (reactant conversions

173 around $30 \%$ ), whereas in the case of the biphasic system, conversions of both

174 reactants are below $5 \%$. These results suggest that mass transfer (enhanced as stirring

175 rate increases) plays a key role in the biphasic system. Taking into account these

176 results, the use of the water/ethyl acetate biphasic system was discarded. Aldol

177 condensation does not take place in organic phase and the interphase transport of the

178 adducts to the organic phase plays a relevant role, hindering the overall process.

179 Reaction by-products derived from the organic solvent were not observed in these

180 experiments.

181 Concerning to the water/ethanol system, reaction conditions must be optimised in

182 order to determine further limitations of this configuration. For this purpose, the

183 evolution of reactants and products with reaction time at $303 \mathrm{~K}$ using $0.1 \mathrm{~g}$ of $\mathrm{MgZr}$

184 and a 1:1 volume ratio water/ethanol as solvent is plotted in Fig. 2. This analysis was

185 not possible with the water/ethyl acetate system, since the biphasic character of this

186 configuration prevents sampling with time (the constant organic/aqueous volume

187 ratio, modifies the temporal ratio evolution between both solvents and, hence,

188 disturbing the whole reaction), thus only the final point was considered. As it is 
189 observed in Fig. 2, the trend in the reactants with the water/ethanol system is

190 analogous - although with lower values - than with water, a continuous decrease until

191 similar final conversions for furfural and cyclopentanone (30\%, approximately). These

192 lower values suggest an inhibition role of the organic phase in the whole condensation,

193 as it was previously observed in other condensations ${ }^{27}$. Water has a key role on

194 catalyst performance, in agreement with the negligible reaction extent in the

195 experiment performed in presence of pure ethanol. Concerning to the reaction

196 products, the main one is the $\mathrm{C} 10$ adduct (in good agreement with the parallel

197 evolution of both reactants), and the production of the C15 adduct is only significant

198 after 3 hours reaction time. The final concentration of both reaction products (C10 and

$199 \mathrm{C} 15)$ is 0.07 and $0.01 \mathrm{~mol} \cdot \mathrm{L}^{-1}$, respectively. The carbon balance in this experiment

200 (considering only liquid phase analyses) was $96 \%$, discarding the presence of side

201 reaction products and the precipitation of the condensation adducts. Accordingly, no

202 solid phase was detected during the reaction when it is performed in the

203 water/ethanol system, whereas in the case of the reaction carried out in aqueous

204 phase, the presence of a solid product was detected from the beginning of the

205 experiment. The absence of flat reactant or product profiles during the experiment

206 suggests that this configuration is promising if these results are improved by modifying

207 some parameters (reaction time, temperature or solvents ratio). The double character

208 of this organic solvent (hydrophobic and hydrophilic) and the good interaction

209 between ethanol and water justifies these results.

210 In order to identify the optimum reaction conditions, the influence of different

211 parameters (water/ethanol ratio, reaction time and temperature) was studied. In 
214 to $323 \mathrm{~K}$ ) was dissolved in the liquid phase. GC analyses corroborate that same 215 concentration was detected in all the cases, demonstrating that C10 and C15 are 216 entirely soluble in all the liquid mixtures tested.

219 Experiments at different water/ethanol ratios (1:0.9 to 1:2) were carried out in order

220 to balance the enhancement of the aldol condensation reaction and the minimization

221 of the reaction products precipitation. Higher ethanol percentages inhibit the

222 condensation, whereas lower amount of the alcohol leads to reaction products

223 precipitation. The temporal evolution of all the compounds involved in the reaction is

224 detailed in Fig. 3. In these studies, the temperature, catalyst loading, and reactant

225 concentration were chosen considering the values previously optimized for the

226 reaction in aqueous phase $(303 \mathrm{~K}, 0.1 \mathrm{~g}$ of $\mathrm{MgZr}$ and $5 \%$ of organics with 1:1 FFL:CPO

227 ratio $)^{12}$. In general terms, same trends were observed in all the cases, concluding that

228 the presence of ethanol in different ratios does not influence the whole mechanism of

229 the reaction. According to this, furfural and cyclopentanone show the typical 230 decreasing profiles of primary reactants (slightly more linear in the case of furfural).

231 The parallel evolutions of both compounds suggest that reaction is mainly limited to 232 the first step, the $\mathrm{C} 10$ formation, main reaction product detected. Only in the last 233 points of the most favourable conditions, the signal of C15 can be clearly appreciated, 234 with a typical behaviour of a secondary product. In order to make easier the analysis of 235 these data, Fig. 4 compares the results after $4 \mathrm{~h}$ at $303 \mathrm{~K}$. A strong influence of 
236 water/ethanol ratio is observed for all the considered parameters. Reactants

237 conversions decrease as the ethanol concentration increases, until $36 \%$ for CPO and

$23846 \%$ for FFL at 1:0.9 water/ethanol ratio. These values strongly decrease to $8 \%$ for

239 CPO and $6 \%$ for FFL at the opposite conditions (1:2 water/ethanol). A huge difference

240 in FFL conversion is observed when water/ethanol changes from 1:0.9 to 1:1, since the

241 furfural conversion is almost $33 \%$ higher with 1:0.9. From the final carbon balance 96

$242 \%$, the presence of solids is discarded for 1:1 test and larger alcohol concentrations.

243 However, for a water/ethanol ratio of 1:0.9, a carbon balance of $89 \%$ is obtained,

244 suggesting a breaking point in the evolution (and a subsequent fast decrease) if higher

245 amounts of water were used. In fact, reaction at these conditions produces the

246 precipitation of condensation adducts (mainly C15), enhancing the formation of this

247 compound and consuming more furfural. In fact, 8.75 moles of C15 were obtained

248 after dissolving the solid recovered after this reaction in ethanol, whereas only 0.88

249 moles of C15 were detected in the liquid phase. The amount of solids obtained is

250 supposed to be much higher at higher water/ethanol ratio, being these configurations

251 discarded for this study.

252 The $\mathrm{C} 10$ and $\mathrm{C} 15$ formation patters are very different. The $\mathrm{C} 10$ atomic yield decreases

253 as the percentage of water increases, reaching final values of 27 and $6 \%$ with 1:0.9

254 and 1:2 water/ethanol ratios, respectively. Considering the positive role of water in the

255 aldol condensation, these data could suggest that higher amounts of water enhance

256 the formation of the second adduct, C15. However, the C15 yield reaches a maximum

257 (5.6 \%) working with the 1:1 mixture. This behaviour is not the expected for a limiting

258 reactant. Therefore, the study of different furfural/cyclopentanone ratios was

259 discarded (the stoichiometric furfural/cyclopentanone ratio is 2:1), taking into account 
260 that reaction is not limited by the total consumption of the reactants, and the

261 water/ethanol ratio is controlling the reaction extent. Therefore, and taking into

262 account the possible side products derived for the furfural adsorption, it was

263 concluded that working with furfural excess has a negative effect on the overall yield.

264 Same conclusion was reported for the furfural-acetone aldol condensation, in which no

265 significant improvement was observed when working with 2:1, being considered the

$2661: 1$ ratio as the optimum one ${ }^{7}$

267 In order to extrapolate the results to higher reactant conversions, reactions at the 268 most representative water/ethanol ratios $(1: 1.35,1: 1.5,1: 2)$ were repeated, but 269 increasing the reaction time to $24 \mathrm{~h}$. Experiments with higher water concentrations 270 were discarded because of the low carbon balances after only $4 \mathrm{~h}$ reaction time. These 271 studies were carried out in order to identify if ethanol has any inhibitory effect in the 272 reaction kinetics (in such a way similar results as in aqueous phase could be obtained 273 at longer times) or if the reaction is limited at given ethanol concentrations. Obtained 274 results are in a good agreement with previously reported trends in all the cases. The 275 temporal evolution of reactants and products are shown in the supplementary 276 information (Fig. S1), whereas the final results are summarized in Table 1 in 277 comparison to the corresponding ones after $4 \mathrm{~h}$, in order to facilitate the direct 278 comparison. Experiments performed at the 1:2 ratio provide clearly different results to 279 the parallel evolution of $1: 1.35$ and $1: 1.5$ reactions. In the two last mentioned 280 experiments, carbon balances markedly decrease to values lower than $60 \%$, with the 281 subsequent precipitation of a solid phase. This fact mainly affects to the C15, which 282 never reaches yields higher than $2.6 \%$, despite conversions close to $80 \%$ of furfural 283 and around $50 \%$ of cyclopentanone were observed. Best results were obtained 
working at 1:2 water/ethanol ratio. At these conditions, 35 and $50 \%$ of cyclopentanone and furfural conversion were reached, remaining the carbon balance

286 close to $100 \%$, and observing significant increases in the C10 and C15 atomic yields.

287 Specically, the C10 atomic yield increases to $26 \%$ and the C15 one to $10.5 \%$. These

288 values are the highest obtained in the liquid phase, even working with aqueous 289 phase $^{12}$ or with water/ethanol mixtures, and correspond to an increase of more than $29075 \%$ of the highest yield reported in the literature.

293 The role of the temperature on the catalyst performance was studied in the range of

$294303-323 \mathrm{~K}$, considering the $1: 1,1: 1.5$ and 1:2 water-ethanol ratios and keeping constant the other parameters ( $0.1 \mathrm{~g}$ of catalyst, $5 \%$ of organics at equimolar ratio).

296 These solvent ratios were chosen as function of the previous results at $303 \mathrm{~K}$ and the 297 expected positive effect of the temperature on the reaction rate. Results after $4 \mathrm{~h}$ of 298 reaction are summarized in Fig. 5. At 1:1 conditions, conversions higher than $50 \%$ of 299 both reactants were obtained at $323 \mathrm{~K}$. These values are the highest observed and are 300 in good agreement with the key role of water in this reaction. In relative terms, an 301 increment in the reaction temperature of $20 \mathrm{~K}$ corresponds to relative increments of

30272.1 and $65.1 \%$ for cyclopentanone and furfural conversions, respectively, at these conditions. Despite conversion decreases when the amount of ethanol in the medium

304 increases, the role of temperature is more relevant, obtaining relative increases of 30548.2 and $116.4 \%$ for cyclopentanone and furfural conversions, working at 1:1.5; and 306147 and $227 \%$, respectively, with the $1: 2$ solvent ratio. Less marked trends were 
307 observed for the evolution of C10 and C15 adducts, except for the 1:1 ratio, where

308 liquid phase yields seem to be limited by lateral reactions involving the C15 (yields

309 constant at $3.5 \%)$. In good agreement, the carbon balance only decreases in this case,

310 suggesting that ethanol concentration is not high enough to dissolve the reaction

311 products. This effect was not observed in the other cases because the maximum

312 amount of C15 was $2.6 \%$. Considering that the aim of this study is to improve the aldol

313 condensation but preventing the precipitation of products, results obtained allow us to

314 conclude that the best configuration is working at 1:2 water/ethanol ratio. At these

315 conditions, a temperature of $323 \mathrm{~K}$ is needed to partially compensate the decrease in

316 the activity when the aldol condensation is carried out in organic solvent. After $4 \mathrm{~h}, \mathrm{a}$

317 global yield of $19.5 \%$ was reached, keeping the carbon balance close to $100 \%$.

318 Reaction at 1:2 solvent ratio and $323 \mathrm{~K}$ was repeated increasing the reaction time to

319 promote the aldol condensation. Final results are summarized in Fig. 6, comparing the

320 improvement between 4, 24 and 48 hours at 303 and $323 \mathrm{~K}$. Concerning to the

321 conversions, the highest improvement was obtained at $323 \mathrm{~K}$, reaching a CPO

322 conversion after $24 \mathrm{~h}$ more than ten times higher than the original one after $4 \mathrm{~h}(51.9$

323 and $4.7 \%$, respectively). However, these conditions are discarded because of the lower

324 carbon balance obtained (66\%), suggesting a high relevance of side reactions and/or

325 product precipitation. In good agreement, reaction at $48 \mathrm{~h}$ was not considered for the

326 study. On the other hand, the highest yields were obtained at $303 \mathrm{~K}$ after $24 \mathrm{~h}$, with a

327 global yield of $36.6 \%$ and a C10/C15 ratio of 2.4. Longer times have not a positive

328 effect in these data, reaching similar yields of the main product when the reaction time

329 increases to $48 \mathrm{~h}$. However, the increase in the conversion, mainly the furfural one, as

330 well as the decrease in the carbon balance (from 93 to $78 \%$, after 24 and $48 \mathrm{~h}$ ), 
331 suggests that reaction times longer than $24 \mathrm{~h}$ promote side reactions. In order to

332 discard solubility limitations, an extra reaction at 1:4 (water/ethanol ratio) was carried

333 out, obtaining same results as in the previous at 1:2 (34.6\% global yield with less than

$33411 \%$ of $\mathrm{C} 15$ ). Analysing all these results, the aldol condensation at 1:2 (water/ethanol

335 ratio) at $303 \mathrm{~K}$ for 24 hours was chosen as the optimum ones for this reaction. At these

336 conditions, global yields are similar as those reported for aldol condensations using

337 furfural as biomass-derived molecule ${ }^{10}$.

\subsection{Reaction mechanism and kinetic modelling}

340 In order to get new insights about the reactivity, as well as to compare with the

341 reactivities reported for similar catalytic systems, initial conversion rate on a mass

342 basis were estimated according to the following equation:

$$
r_{\text {condensation }}^{0}=\frac{1}{S_{G}} \cdot\left[\frac{d X}{d\left(\frac{t \cdot W}{n^{0}}\right)}\right]_{\left(\frac{t \cdot W}{n^{0}}\right)=0}
$$

344 Where " $\mathrm{S}_{\mathrm{G}}$ " is the surface area of the catalyst $\left(74 \mathrm{~m}^{2} \cdot \mathrm{g}^{-1}\right.$ for this $\mathrm{Mg}-\mathrm{Zr}$, as it was

345 previously reported ${ }^{7,8}$ ); " $\mathrm{X}$ " the aldehyde conversion; " $\mathrm{t}$ " the reaction time in minutes;

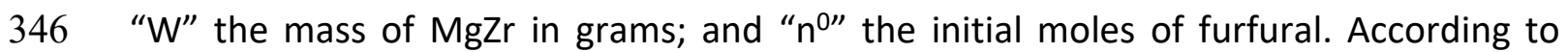

347 experimental results, the initial conversion rate obtained with 1:2 water/ethanol ratio,

348 at $303 \mathrm{~K}$ using $0.1 \mathrm{~g}$ of $\mathrm{Mg}-\mathrm{Zr}$ and $5 \%$ of organics is $2.45 \mu \mathrm{mol} \cdot \mathrm{min}^{-1} \cdot \mathrm{m}^{-2}$, whereas the

349 corresponding value working in aqueous phase has a value of $38.4 \mu \mathrm{mol} \cdot \mathrm{min}^{-1} \cdot \mathrm{m}^{-2}$.

350 Despite the effect of ethanol, this reaction is still much faster than other

351 condensations using furfural and acetone $\left(0.27 \mu \mathrm{mol} \cdot \mathrm{min}^{-1} \cdot \mathrm{m}^{-2}\right)^{7}$ or $5-\mathrm{HMF}$ and acetone

$352 \quad\left(1.9 \mu \mathrm{mol} \cdot \mathrm{min}^{-1} \cdot \mathrm{m}^{-2}\right)^{8}$. 
353 According to the temporal profiles obtained in all the experiments, and the similarity

354 between these data and the previous ones reported in aqueous phase ${ }^{12}$, the first

355 mechanistic conclusion is that the presence of ethanol does not modify the general

356 reaction network, only limiting the reaction rate of the different steps. Considering this

357 mechanism, acid-basic pairs are needed to catalyse these reactions. In fact, the aldol

358 condensation requires the initial abstraction of one $\alpha$-proton from cyclopentanone,

359 obtaining an enolate that attacks the carbonyl group of the furfural molecule.

360 According to the literature, both molecules must be adsorbed on an acid site but

361 Bronsted basicity is also needed to stabilize the proton ${ }^{7,15}$. These Bronsted basic sites

362 are mainly generated by the partial rehydration of the MgZr mixed oxide. This

363 mechanism, as well as the stabilisation of the resulting enolate, justifies the key role of

364 water in the first stages of the reaction, and it is congruent with the negligible

365 conversion observed when working with organic solvents. Once this enolate is

366 stabilized, alcohol intermediate is formed by the nucleophilic attack of the enolate to

367 the furfural carbonyl group. This intermediate is not observed because it undergoes

368 fast dehydration in presence of medium acid sites, yielding the first condensation

369 adduct (C10). The second condensation step is also possible since this molecule (C10)

370 has another $\alpha$-proton, yielding the C15 alcohol and the subsequent C15 condensation

371 adduct after the above-mentioned dehydration step.

372 In agreement with the proposed mechanism, both C10 and C15 adducts are obtained

373 following a first-order dependence on the concentration of the compound undergoing

374 enolization (cyclopentanone and C10, respectively) and zero-th order dependence on

375 furfural. This zero-th order for the furfural is congruent with other kinetics models for

376 the aldol condensation of other bio-platform molecules, such as furfural, $5-\mathrm{HMF}^{8}$ and 
377 citral $^{28}$ with acetone and it is justified by the strong adsorption of furfural on these

378 materials. According to these facts, the kinetic model is described in the following 379 equations (5-8):

$$
\frac{d C_{C P O}}{d t}=-k_{1} \cdot C_{C P O}
$$

$$
\frac{d C_{C 10}}{d t}=k_{1} \cdot C_{C P O}-k_{2} \cdot C_{C 10}
$$

Temporal profiles of reactants and products concentrations were fitted to this kinetic model using the Scientist ${ }^{\circledR}$ software. Ideal batch reactor behaviour has been considered in all the cases. The presence of mass-transfer effects has been discarded by both, ensuring that particle size and stirring reaction do not affect the results, and by theoretical considerations. The theoretical approach consisted on a kinetic model

389 derivation considering the liquid-solid mass transfer and the Thiele modulus-based

390 efficiency factor for internal diffusion. Taking into account the experimental

391 conditions, the resistance due to the intrinsic kinetic is seven orders of magnitude

392 higher than the mass-transfer resistance, the influence of both, external and internal

393 diffusion, was discarded and reaction is considered to be under kinetic control ${ }^{29,} 30$.

394 Table 2 summarises the values $k_{1}$ and $k_{2}$ for all the experiments performed with water-

395 ethanol mixtures. Values of these kinetic constants are normalised considering the catalytic loading and the feed volume in order to compare the results obtained in experiments at different conditions. The correlation coefficient obtained in each case, as well as confidence intervals, were also included in Table 2 for illustrating the 
399 goodness of the fit $\left(r^{2}>0.99\right.$ in all the cases). Other reaction orders were tested, such as

400 first order dependence on FAL concentration or fractional reaction orders, with largely

401 worst results. The correspondence between experimental results and model 402 predictions is shown in the Figures 2 and 3, as well as in the Supplementary

403 Information (Fig. S2). As it could be expected, values of $k_{1}$ were higher than $k_{2}$, 404 concluding that the formation of the first condensation adduct is much faster than the 405 second one. Considering the high amount of solids obtained when the reaction was 406 performed in pure water, the direct comparison between these values and the 407 corresponding ones in aqueous phase is not possible. However, there is a clear 408 influence of the percentage of ethanol and the values of kinetic constants, decreasing 409 as ethanol concentration in the reaction medium increases. If results at 1:0.9 and 1:2 410 are compared, there is a decrease of almost 85 and $63 \%$ in the values of $k_{1}$ and $k_{2}$, 411 respectively. This result is in a good agreement with the previous hypothesis about the 412 key role of the water to promote the aldolization, and the negative effect of ethanol 413 on the general rate. In order to illustrate this idea, Fig. 7 shows the relationship

414 between the ethanol concentration in the different mixtures ethanol/water used in 415 this work and the values of the kinetic constants, observing clearly the decreasing 416 trend of both parameters, being more relevant in the case of the first constant. The 417 observed behaviour suggests a value of this kinetic constants of 0.0114 and 0.0060 $418 \mathrm{~L} \cdot \mathrm{min}^{-1} \cdot \mathrm{g}^{-1}$ for $\mathrm{k}_{1}$ and $\mathrm{k}_{2}$, respectively, when reaction is carried out in aqueous phase.

419 Observing the good fit between the kinetic constant and the ethanol percentage, a 420 clear influence of the solvent polarity is suggested (ethanol/water polarity ratios is 421 0.654). At this point, the presence of polar molecules is considered as necessary for 422 stabilizing the ketone-derived enolate species, needed for accomplishing the 
424 in the adsorption of reaction and/or products is ruled out since the affinity of the

425 surface for ethanol is largely lower than the affinity for water, which is present in all

426 the experiments.

427 Considering the influence of the temperature observed in this study, kinetic constants obtained with experiments at 1:1, 1:1.5 and 1:2 water/ethanol ratio were fit to an Arrhenius dependence. The fit of these constants to this model is plotted in Fig. $\mathbf{8 a}$. The mathematical analysis of these results indicates a continuous increase in the apparent activation energy as the percentage of ethanol in the system increases, obtaining values of $22.8 \mathrm{~kJ} \cdot \mathrm{mol}^{-1}$ for $1: 1.5$, and $49.4 \mathrm{~kJ} \cdot \mathrm{mol}^{-1}$ for $1: 2$. In any case, these data are within the range of values reported in the literature for similar type of reactions ${ }^{8}, 32,33$. At this point, different physical and chemical constraints could influence this parameter when working in liquid phase, thus activation energies are

436 not comparable to those obtained in gas phase. Considering that the apparent 437 activation energy is obtained by the slope of the regression, the corresponding one for 438 the aqueous phase system was estimated taking into account the variation in the initial conversion rates at different temperatures. Result obtained, $7.2 \mathrm{~kJ} \cdot \mathrm{mol}^{-1}$, allows

440 predicting the evolution of the reaction with the water/ethanol ratio, as it is observed

441 in the Fig. $\mathbf{8 b}$. In this figure, the clear inhibitory effect of the organic solvent is 442 observed. The resulting exponential trend justifies ethanol ratios higher than 1:2 must 443 be discarded because of the expected low activity. However, the best results obtained 444 for 1:2 water:ethanol ratio (36.5\% of global yield with this configuration, whereas less 445 than $6 \%$ was obtained as liquids in aqueous solution at the optimized conditions) 446 justify the use of ethanol in the reaction media. In addition, the presence of ethanol 
447 minimises the deactivation caused by the permanent adsorption of main and side

448 reaction products. Globally, this effect compensates the decrease in the kinetic rate,

449 obtaining a net enhancement in the selectivity of C10 and C15.

450

451

4. Conclusions

452 The condensation yields obtained by the reaction between cyclopentanone and

453 furfural are strongly improved by adding ethanol to the initial aqueous phase.

454 According to experimental results, an equilibrium between condensation activity

455 (being water needed) and products solubility (strongly enhanced by the presence of

456 ethanol) is needed. Once reaction time, temperature and water/ethanol ratio were

457 optimized, best results were obtained working at $303 \mathrm{~K}$ and a water/ethanol ratio of

458 1:2. At these conditions, after 24 hours, the global yield in the liquid phase $(36.5 \%)$ is

459 more than six times the maximum ones reported in aqueous phase. The good carbon

460 balance obtained at these conditions (higher than $90 \%$ whereas it was only $24 \%$ in

461 aqueous phase) also corroborates the absence of side reactions and oligomerizations

462 that could have a negative effect in the catalytic deactivation. Experimental data were

463 successfully fit to a first-order reaction mechanism, obtaining a clear dependency

464 between the activation energy and the percentage of ethanol in the mixture.

465

466 ACKNOWLEDGMENTS

467 This work was supported by the Spanish Ministry for Economy and Competitiveness

468 (MINECO) (contract CTQ2014-52956-C3-1-R) 
472 FFL, furfural; CPO, cyclopentanone; HPLC, high performance liquid chromatography; 5-

473 HMF, 5-hydroximethylfurfural; GC, Gas Chromatography.

1. Faba L, Díaz E, Ordóñez S. Recent developments on the catalytic technologies

478 for the transformation of biomass into biofuels: A patent survey. Renew Sust Energ

479 Rev. 2015;51:273-87.

480 2. Huber GW, Chheda JN, Barrett CJ, Dumesic JA. Production of liquid alkanes by 481 aqueous-phase processing of biomass-derived carbohydrates. Science. 2005;308:144648250.

483 3. Hronec M, Fulajtárova K, Liptaj T, Prónayová N, Soták T. Bio-derived fuel 484 additives from furfural and cyclopentanone. Fuel Process Technol. 2015;138:564-9.

485 4. Liang D, Li G, Liu Y, Wu J, Zhang X. Controllable self-aldol condensation of 486 cyclopentanone over $\mathrm{MgO}-\mathrm{ZrO}_{2}$ mixed oxides: Origin of activity \& selectivity. Catal 487 Commun. 2016;81:33-6.

488 5. Hora L, Kelbichová V, Kikhtyanin O, Bortnovskiy O, Kubička D. Aldol 489 condensation of furfural and acetone over $\mathrm{MgAl}$ layered double hydroxides and mixed 490 oxides. Catal Today. 2014;223:138-47.

491 6. Nguyen Thanh D, Kikhtyanin O, Ramos R, Kothari M, Ulbrich P, Munshi T, et 492 al. Nanosized $\mathrm{TiO}_{2}-\mathrm{A}$ promising catalyst for the aldol condensation of furfural with 493 acetone in biomass upgrading. Catal Today. 2016;277:97-107.

$4947 . \quad$ Faba L, Díaz E, Ordóñez S. Aqueous-phase furfural-acetone aldol condensation 495 over basic mixed oxides. Appl Catal B. 2012;113-114:201-11. 
496 8. Cueto J, Faba L, Díaz E, Ordóñez S. Performance of basic mixed oxides for 497 aqueous-phase 5-hydroxymethylfurfural-acetone aldol condensation. Appl Catal B. 498 2017;201:221-31.

499 9. Olcay H, Subrahmanyam AV, Xing R, Lajoie J, Dumesic JA, Huber GW. 500 Production of renewable petroleum refinery diesel and jet fuel feedstocks from 501 hemicellulose sugar streams. Energy Environ Sci. 2013;6:205-16.

502 10. West RM, Liu ZY, Peter M, Gärtner CA, Dumesic JA. Carbon-carbon bond 503 formation for biomass-derived furfurals and ketones by aldol condensation in a biphasic 504 system. J Mol Catal A. 2008;296:18-27.

505 11. Wang Y, Sang S, Zhu W, Gao L, Xiao G. CuNi@C catalysts with high activity 506 derived from metal-organic frameworks precursor for conversion of furfural to 507 cyclopentanone. Chem Eng J. 2016;299:104-11.

508 12. Cueto J, Faba L, Díaz E, Ordonez S. Cyclopentanone as alternative linking 509 reactant for heterogeneously catalysed furfural aldol condensation. ChemCatChem. $510 \quad 2017 ; 9: 1765-70$.

511 13. Hronec M, Fulajtárova K, Liptaj T, Štolcová M, Prónayová N, Soták T. 512 Cyclopentanone: A raw material for production of $\mathrm{C} 15$ and $\mathrm{C} 17$ fuel precursors. 513 Biomass Bioenergy. 2014;63:291-9.

514 14. Deng Q, Xu JS, Han PJ, Pan L, Wang L, Zhang XW, et al. Efficient synthesis of 515 high-density aviation biofuel via solvent-free aldol condensation of cyclic ketones and 516 furanic aldehydes. Fuel Process Technol. 2016;148:361-6.

517 15. Hora L, Kikhtyanin O, Čapek L, Bortnovskiy O, Kubička D. Comparative study 518 of physico-chemical properties of laboratory and industrially prepared layered double 519 hydroxides and their behavior in aldol condensation of furfural and acetone. Catal 520 Today. 2015;241:221-30.

521 16. Wu KJ, Wu YL, Chen Y, Chen H, Wang JL, Yang MD. Heterogeneous 522 Catalytic Conversion of Biobased Chemicals into Liquid Fuels in the Aqueous Phase. 523 ChemSusChem. 2016;9:1355-85.

524 17. Kikhtyanin O, Tisler Z, Velvarska R, Kubicka D. Reconstructed Mg-Al 525 hydrotalcites prepared by using different rehydration and drying time: Physico-chemical 526 properties and catalytic performance in aldol condensation. Appl Catal A. 2017;536:8552796. 
528 18. Wang W, Ji XH, Ge HG, Li ZZ, Tian GH, Shao XZ, et al. Synthesis of C15 and 529 C10 fuel precursors with cyclopentanone and furfural derived from hemicellulose. RSC 530 Adv. 2017;7:16901-7.

531 19. Shinde VM, Patil GN, Katariya A, Mahajan YS. Production of tetrahydrofuran 532 by dehydration of 1,4-butanediol using Amberlyst-15: Batch kinetics and batch reactive 533 distillation. Chem Eng Process. 2015;95:241-8.

534 20. Richter P. Methanol Encyclopedia of Toxicology (Third Edition). Oxford: 535 Academic Press; 2014. p. 238-41.

536 21. Faba L, Diaz E, Vega A, Ordonez S. Hydrodeoxygenation of furfural-acetone 537 condensation adducts to tridecane over platinum catalysts. Catal Today. 2016;269:1325389.

539 22. Henderson RK, Jiménez-González C, Constable DJC, Alston SR, Inglis GGA, 540 Fisher G, et al. Expanding GSK's solvent selection guide - embedding sustainability into 541 solvent selection starting at medicinal chemistry. Green Chem. 2011;13:854-62.

542 23. de Barros EM, Carvalho VM, Rodrigues THS, Rocha MVP, Gonçalves LRB. 543 Comparison of strategies for the simultaneous saccharification and fermentation of 544 cashew apple bagasse using a thermotolerant Kluyveromyces marxianus to enhance 545 cellulosic ethanol production. Chem Eng J. 2017;307:939-47.

546 24. Strohm B. Ethanol. Encyclopedia of Toxicology (Third Edition). Oxford: 547 Academic Press; 2014. p. 488-91.

548 25. Scanlon JT, Willis DE. Calculation of Flame Ionization Detector Relative 549 Response Factors Using the Effective Carbon Number Concept. J Chromatogr Sci. $550 \quad 1985 ; 23: 333-40$.

551 26. Sengwa RJ, Sankhla S. Characterization of heterogeneous interaction in binary 552 mixtures of ethylene glycol oligomer with water, ethyl alcohol and dioxane by dielectric 553 analysis. J Mol Liq. 2007;130:119-31.

554 27. Faba L, Díaz E, Ordóñez S. One-pot Aldol Condensation and 555 Hydrodeoxygenation of Biomass-derived Carbonyl Compounds for Biodiesel Synthesis. 556 ChemSusChem. 2014;7:2816-20.

557 28. Díez VK, Apesteguía CR, Di Cosimo JI. Aldol condensation of citral with 558 acetone on $\mathrm{MgO}$ and alkali-promoted MgO catalysts. J Catal. 2006;240:235-44. 
559 29. Fogler HS. Elements of Chemical Reaction Engineering: Pearson Education; 5602016.

561 30. Ordóñez S, Vivas BP, Díez FV. Minimization of the deactivation of palladium 562 catalysts in the hydrodechlorination of trichloroethylene in wastewaters. Appl Catal B. 563 2010;95:288-96.

564 31. Climent MJ, Corma A, Iborra S. Conversion of biomass platform molecules into 565 fuel additives and liquid hydrocarbon fuels. Green Chem. 2014; 16: 516 -547.

566 32. O’Neill RE, Vanoye L, De Bellefon C, Aiouache F. Aldol-condensation of 567 furfural by activated dolomite catalyst. Appl Catal B. 2014;144:46-56.

568 33. Casanova O, Iborra S, Corma A. Biomass into chemicals: One pot-base free 569 oxidative esterification of 5-hydroxymethyl-2-furfural into 2,5-dimethylfuroate with 570 gold on nanoparticulated ceria. J Catal. 2009;265:109-16. 


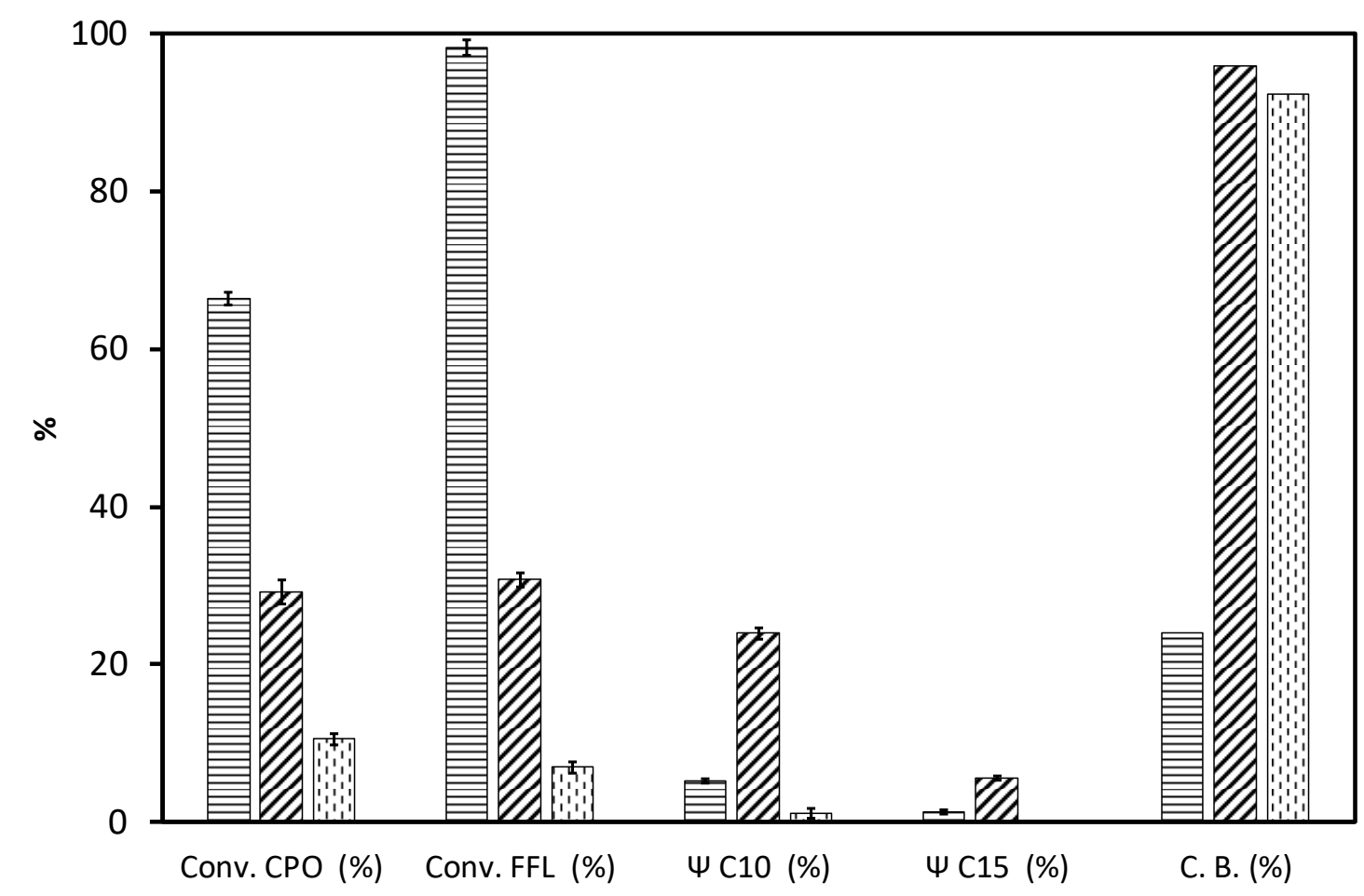

573

574 Fig. 1. Results obtained, considering only liquid phase composition, after $4 \mathrm{~h}$ of furfural

575 and cyclopentanone aldol condensation at $303 \mathrm{~K}$ catalyzed by $0.1 \mathrm{~g}$ of $\mathrm{MgZr}$ using

576 different systems: aqueous system (bars with horizontal lines) and two different

577 water/organic systems: 1:1 water/ethanol (bars with twisted lines), and 1:1

578 water/ethyl acetate (bars with vertical lines). Results in terms of reactant conversions,

579 product atomic yields and carbon balance.

580

581

582

583

584

585

586

587

588 


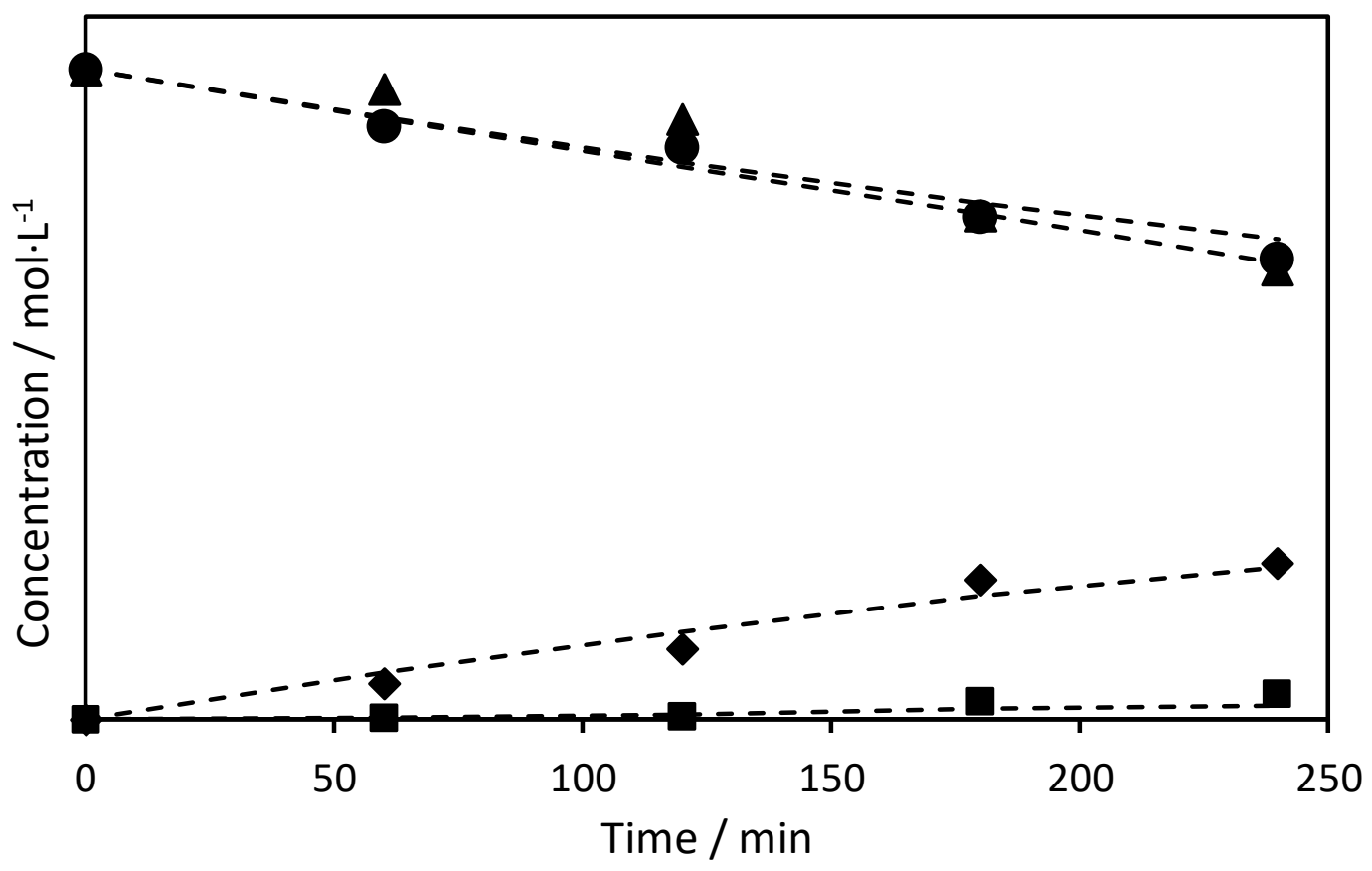

590 Fig. 2. Reactants and products concentration temporal evolution of the cyclopentanone -

591 furfural condensation (5\% organics, 1:1 water/ethanol ratio, $303 \mathrm{~K}$ and $0.1 \mathrm{~g}$ of $\mathrm{Mg} \mathrm{Zr}$ ).

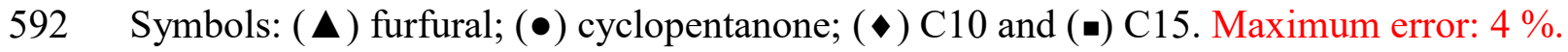

593 Lines correspond to the predictions of the proposed kinetic model. 

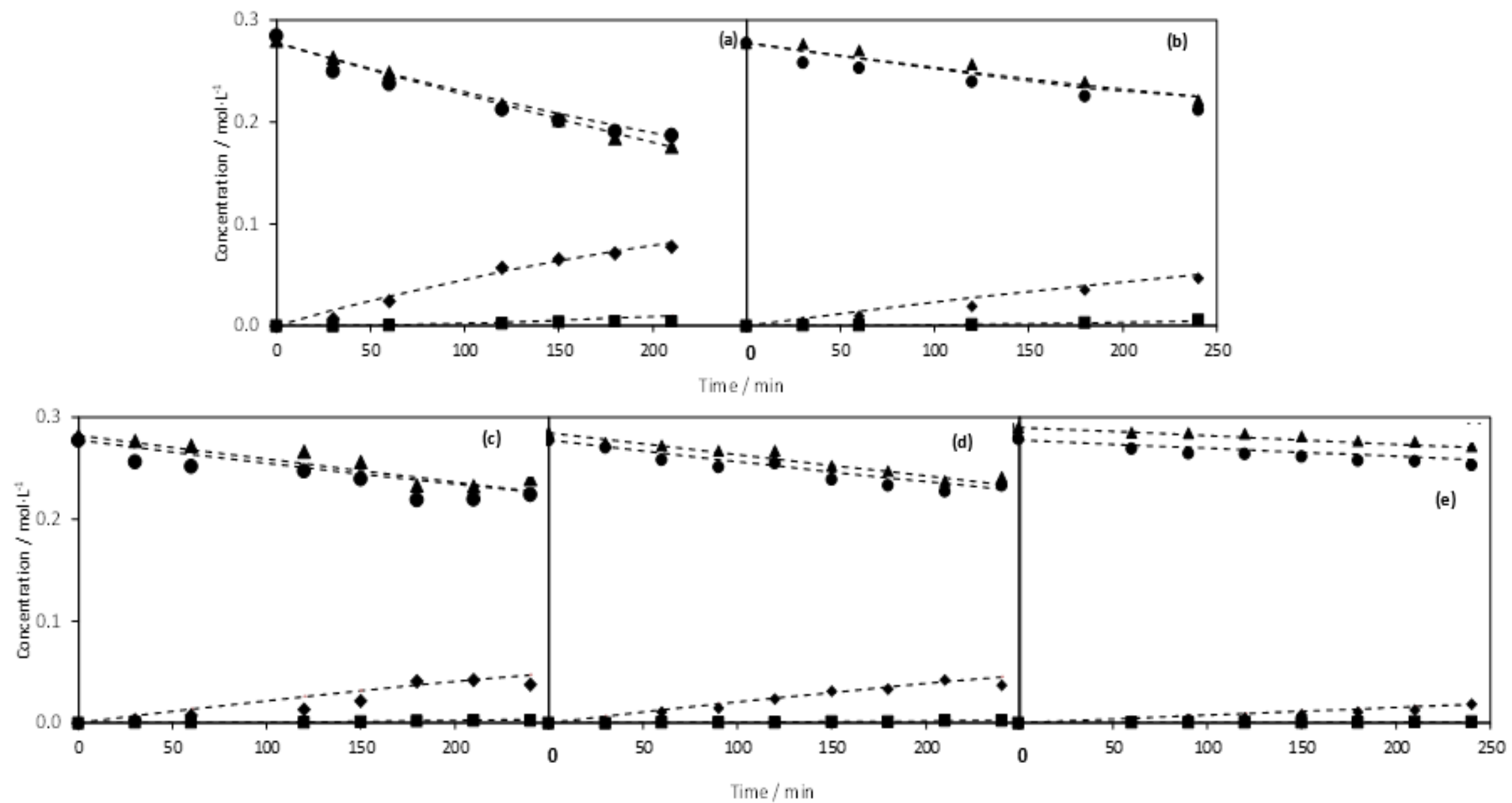

Fig. 3. Evolution of reactants and products concentration involved in the aldol condensation of cyclopentanone and furfural (303 K, $0.1 \mathrm{~g} \mathrm{Mg}-\mathrm{Zr}$, 1:1 Furfural:Cyclopentanone) as function of reaction time for different ethanol-water mixtures: (a) 1:0.9; (b) 1:1.35; (c) 1:1.5; (d) 1:1.75; (e) 1:2. Symbols: $(\boldsymbol{\Delta})$ furfural; $(\bullet)$ cyclopentanone; $(\bullet) \mathrm{C} 10$ and $(\bullet)$ C15. Maximum error of $3.75 \%$. Lines correspond to the predictions of the proposed kinetic model. 


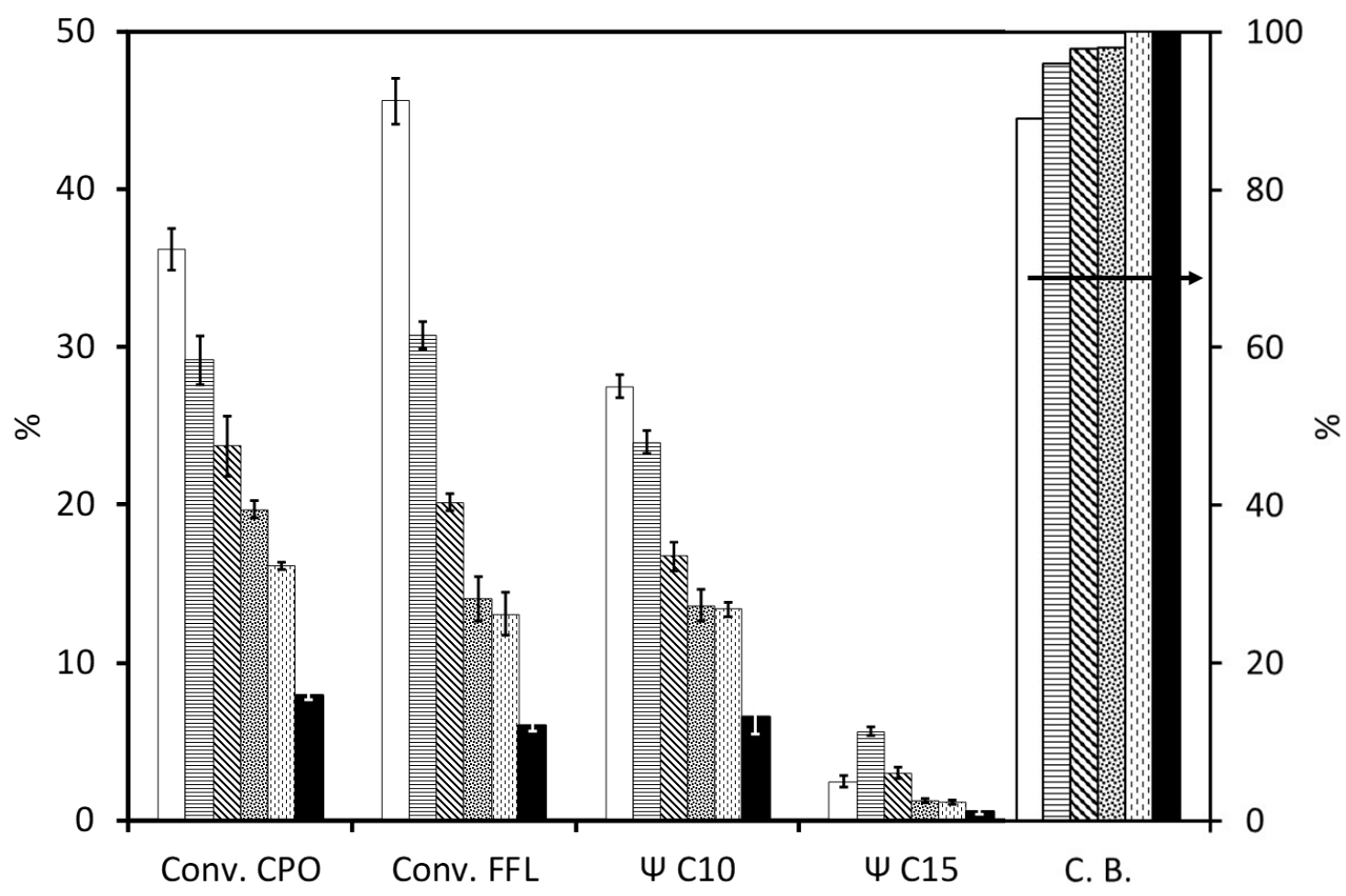

Fig. 4. Results obtained after $4 \mathrm{~h}$ of furfural and cyclopentanone aldol condensation at $303 \mathrm{~K}$ catalyzed by $0.1 \mathrm{~g}$ of MgZr using different initial water/ethanol ratio: 1:0.9 (white), 1:1 (bars with horizontal lines), 1:1.35 (bars with twisted lines), 1:1.5 (dotted bars), 1:1.75 (bars with vertical lines) and 1:2 (solid black). Results in terms of reactants conversions, product atomic yields and carbon balance (secondary axe). 


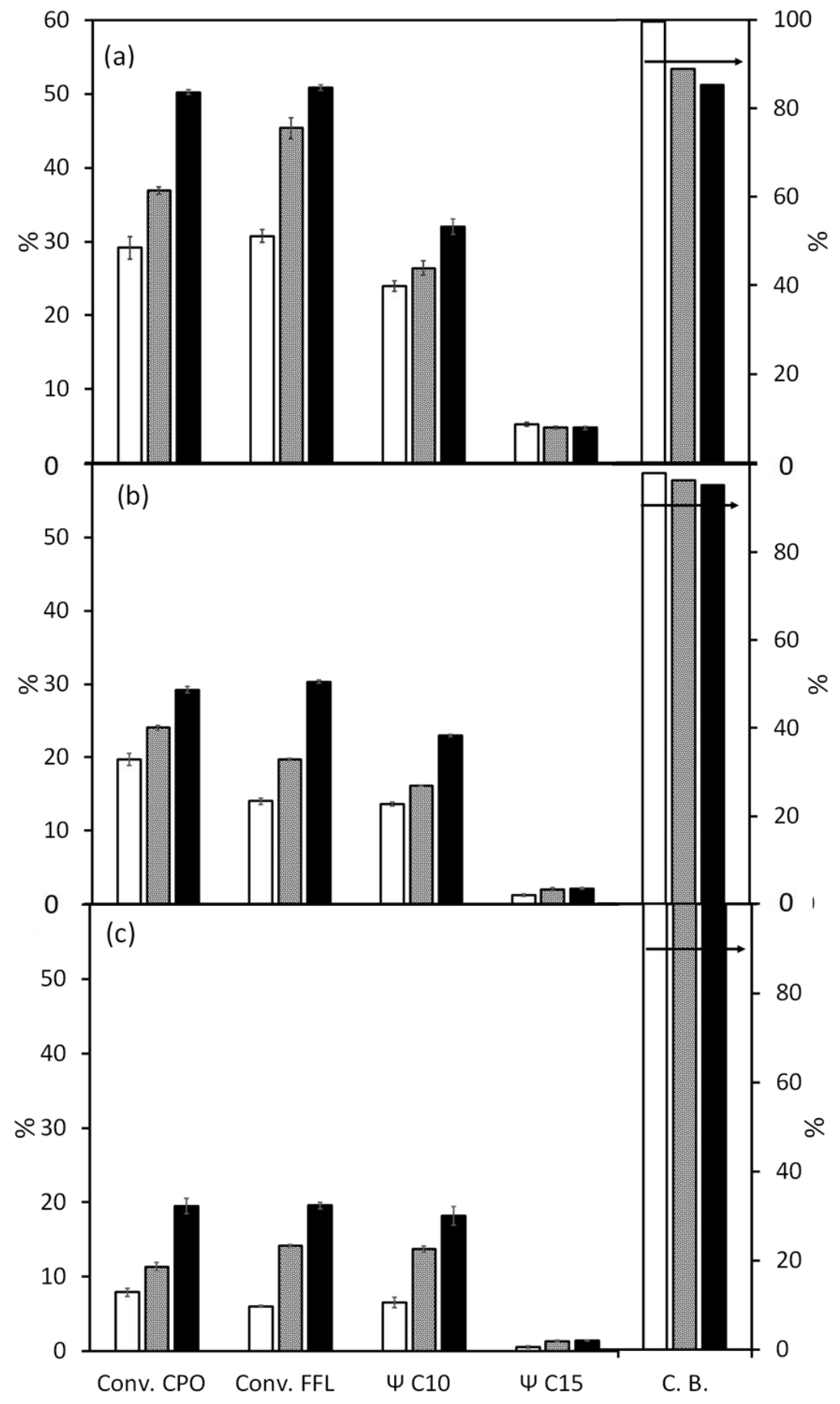

Fig. 5. Results obtained after $4 \mathrm{~h}$ of furfural and cyclopentanone aldol condensation catalyzed by $0.1 \mathrm{~g}$ of MgZr using different water/ethanol ratios: (a) 1:1; (b) 1:1.5, (c) 1:2. Reaction temperature: $303 \mathrm{~K}$ (white); $313 \mathrm{~K}$ (grey); $323 \mathrm{~K}$ (black). 


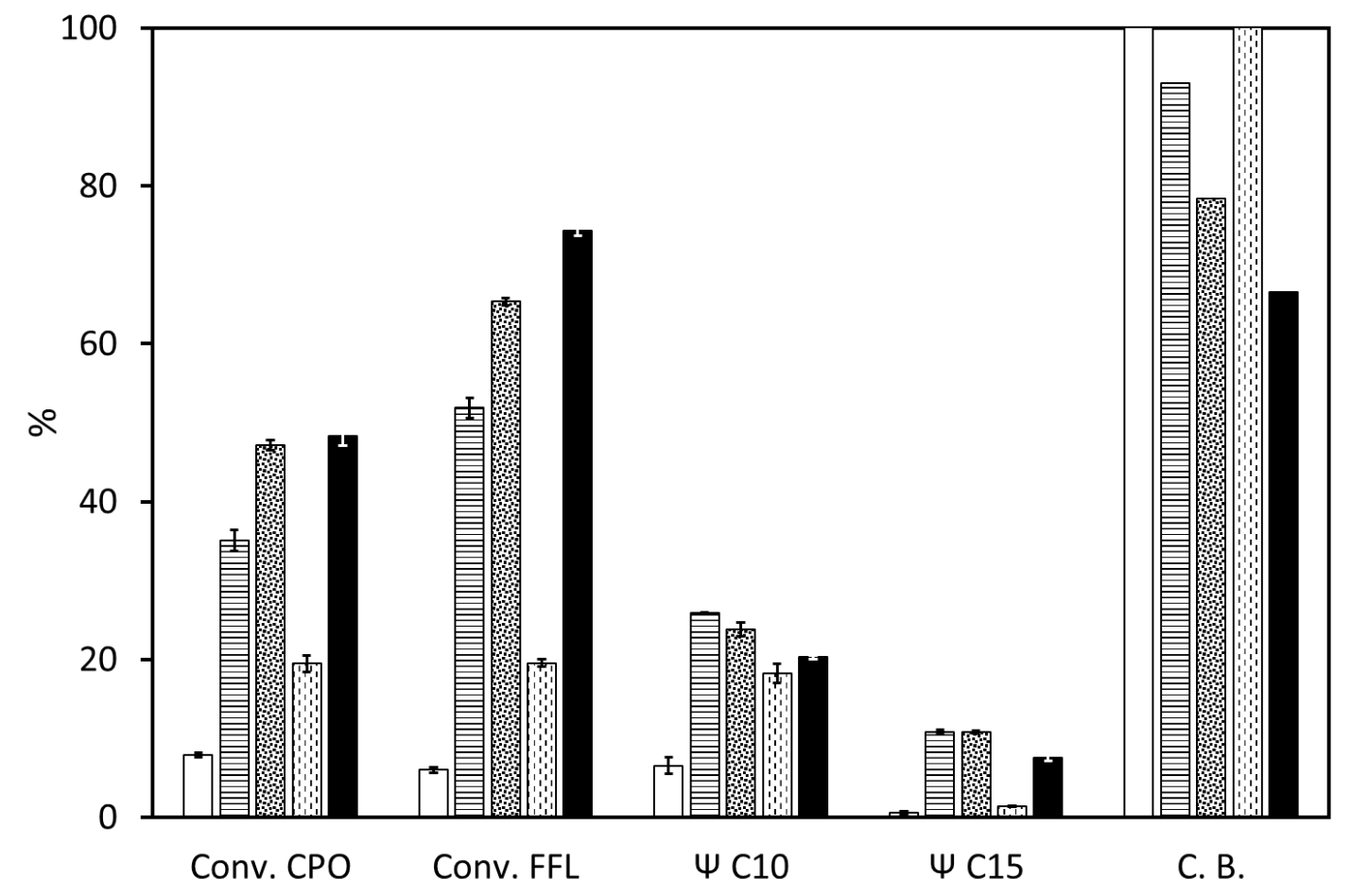

Fig. 6. Comparison of the results obtained in the CPO-FFL aldol condensation using 1:2 water/ethanol ratio and $0.1 \mathrm{~g}$ of $\mathrm{MgZr}$ as function of the temperature and the reaction time. Legend: $303 \mathrm{~K}$ and $4 \mathrm{~h}$ (white); $303 \mathrm{~K}$ and $24 \mathrm{~h}$ (bars with horizontal lines); $303 \mathrm{~K}$ and $48 \mathrm{~h}$ (dotted bars); $323 \mathrm{~K}$ and $4 \mathrm{~h}$ (bars with vertical lines); $323 \mathrm{~K}$ and $24 \mathrm{~h}$ (black). 


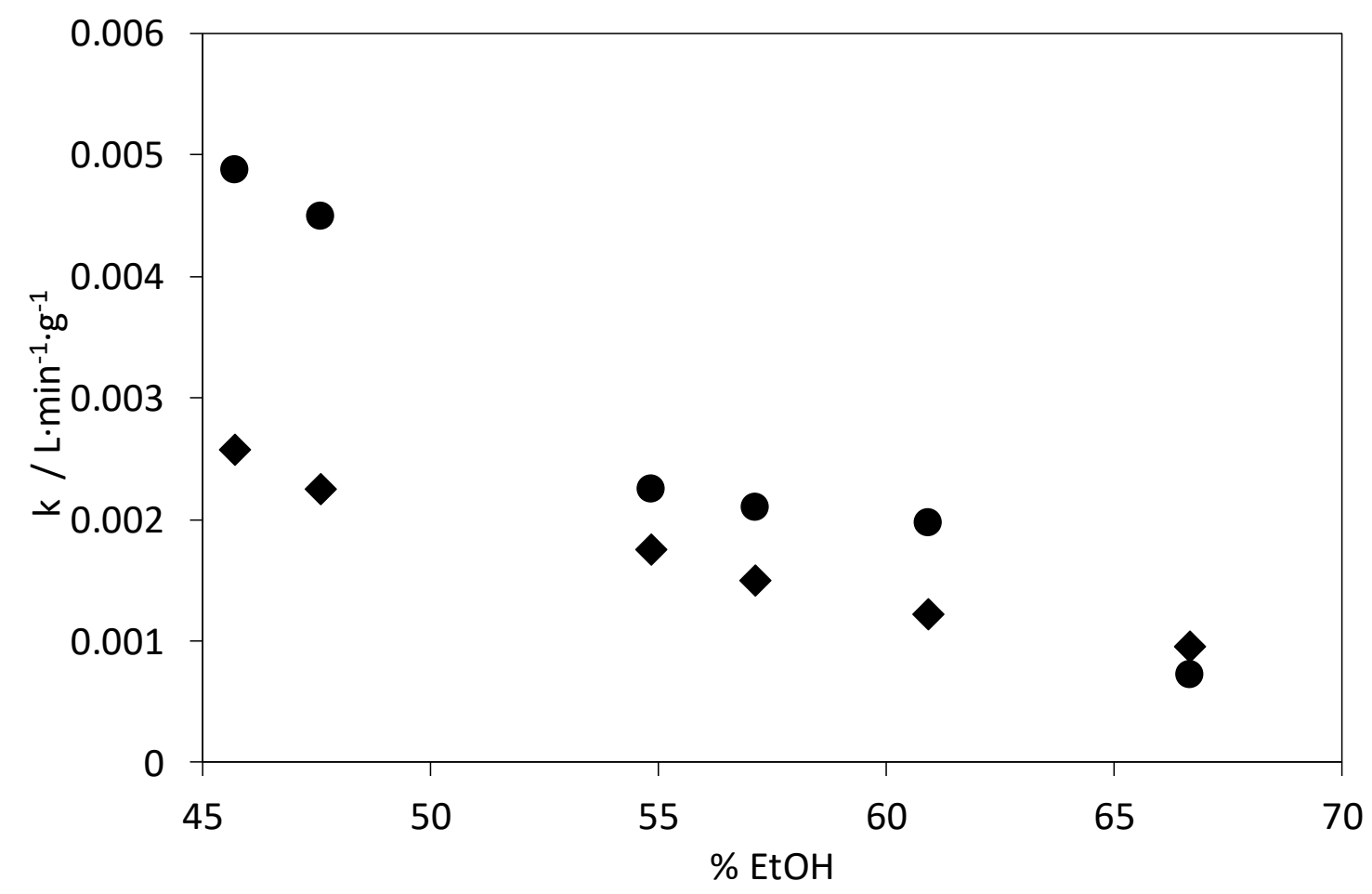

Fig. 7. Kinetic constants for the fitting of the experimental results to the proposed kinetic model when different percentages of ethanol were used in the feed at $303 \mathrm{~K}$. Symbols: $(\bullet) \mathrm{k}_{1} ;(\bullet) \mathrm{k}_{2}$. 

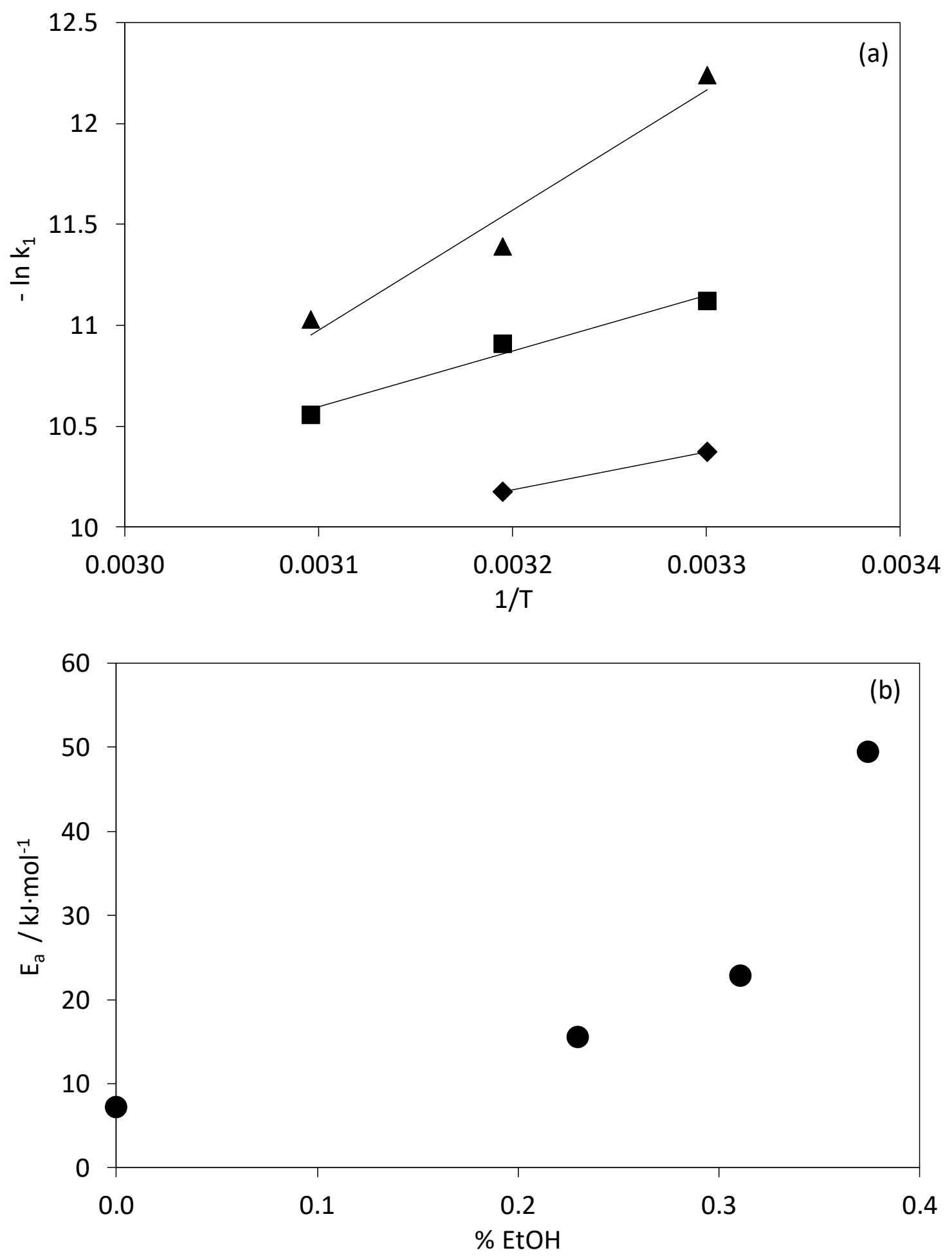

Fig. 8. Analysis of kinetic data with temperature. (a) Arrhenius adjustment for different

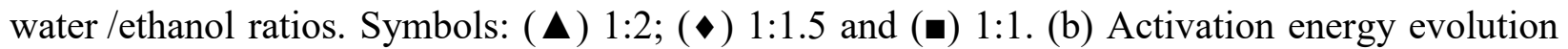
with the percentage of ethanol used in the feed. 
Table 1. Results of condensation between furfural and cyclopentanone ( $5 \%$ of cyclic molecules, $303 \mathrm{~K}$ ) catalyzed by $0.1 \mathrm{~g}$ of $\mathrm{MgZr}$ at different times and solvent relations.

\begin{tabular}{ccccccc}
\hline Time (h) & Water/Ethanol & Conv. CPO (\%) & Conv. FFL (\%) & $\Psi$ C10 & $\Psi$ C15 & C. B. \\
\hline 4 & $1: 1.35$ & 23.7 & 20.2 & 16.7 & 3.0 & 97.8 \\
24 & $1: 1.35$ & 50.0 & 79.4 & 22.1 & 2.6 & 59.9 \\
4 & $1: 1.5$ & 19.7 & 14.0 & 13.6 & 1.3 & 98.0 \\
24 & $1: 1.5$ & 54.7 & 78.5 & 21.6 & 2.4 & 57.4 \\
4 & $1: 2$ & 7.9 & 6.0 & 6.5 & 0.6 & 100.0 \\
24 & $1: 2$ & 35.9 & 51.2 & 25.9 & 10.8 & 93.1 \\
\hline
\end{tabular}


Table 2. Kinetic constants for the fitting of the experimental results to the proposed kinetic model when MgZr was used as catalyst (see equations 4-7 to identify the constants). Values reported with $95 \%$ confidence interval $(\mathrm{Cl})$.

\begin{tabular}{ccccc}
\hline Temperature (K) & Water/Ethanol & $\mathbf{k}_{1}\left(\mathrm{~L} \cdot \mathrm{min}^{-1} \cdot \mathrm{g}^{-1}\right)$ & $\mathbf{k}_{\mathbf{2}}\left(\mathrm{L} \cdot \mathrm{min}^{-1} \cdot \mathrm{g}^{-1}\right)$ & $\mathbf{r}^{\mathbf{2}}$ \\
\hline $1: 0.9$ & $0.0049 \pm 0.0003$ & $0.0025 \pm 0.0005$ & 0.996 \\
$1: 1$ & $0.0045 \pm 0.0003$ & $0.0023 \pm 0.0007$ & 0.996 \\
303 & $1: 1.35$ & $0.0023 \pm 0.008$ & $0.0018 \pm 0.0008$ & 0.998 \\
& $1: 1.5$ & $0.0021 \pm 0.0005$ & $0.0015 \pm 0.0002$ & 0.997 \\
& $1: 1.75$ & $0.0020 \pm 0.0006$ & $0.0012 \pm 0.0003$ & 0.999 \\
& $1: 2$ & $0.0007 \pm 0.0002$ & $0.0009 \pm 0.0001$ & 0.999 \\
\hline 313 & $1: 1$ & $0.0057 \pm 0.0005$ & $0.0044 \pm 0.0001$ & 0.995 \\
& $1: 1.5$ & $0.0024 \pm 0.0002$ & $0.0018 \pm 0.0003$ & 0.995 \\
& $1: 2$ & $0.0017 \pm 0.0009$ & $0.0003 \pm 0.0001$ & 0.999 \\
\hline 323 & $1: 1.5$ & $0.0039 \pm 0.0005$ & $0.0021 \pm 0.0002$ & 0.999 \\
& $1: 2$ & $0.0024 \pm 0.0007$ & $0.0008 \pm 0.0001$ & 0.997 \\
\hline
\end{tabular}




\section{ASSOCIATED CONTENT}

\section{Supporting Information}

Comparison of experimental results and fitted data is available, for all the experiments of the study, in the supporting information.

\section{AUTHOR INFORMATION}

\section{Corresponding Author}

*Tel.: +34 985103 437; Fax: + 34985103434.

e-mail address: sordonez@uniovi.es (S. Ordóñez) 